\title{
Food and nutrition in palliative care: a survey done by the Food and Nutrition Group at Help the Hospices
}

\author{
E. Tsiompanou \\ Help the Hospices, Hospice House, 34-44 Britannia Street, London WC1X 9JG, UK
}

The Food and Nutrition Group at Help the Hospices was formed in July 2006. The aims of the group are to establish a network of professionals working in palliative care who have identified roles within their organisation for nutritional care and to inform the development of quality standards for nutritional care in palliative care.

In 2007 the group devised a survey, which was circulated to all hospices in the UK. It looked at various aspects of nutrition and was intended to help the group gain a better understanding of the key issues in this area. In total 240 questionnaires were sent out, of which seventy-six returns were received (32\%). The following information was gathered: (1) it was difficult to identify a lead in nutritional care within the hospices. Often a multidisciplinary approach was preferred (22\%) or the nursing team took the lead (21\%); (2) most hospices had a designated catering team (95\%); (3) dietetic needs were catered for by dialogue with the patient, nursing staff and catering team (36\%), while $26 \%$ used the advice of a dietitian; (4) hospices reported using a combination of nurses, doctors, dietitians and other professionals to offer nutritional advice; (5) most respondents (64\%) felt equipped to offer nutritional advice; (6) 55\% of hospices did not have a dietitian, while some $(32 \%)$ had access to one; (7) the majority of hospices $(54 \%)$ did not provide teaching on nutritional issues; (8) almost all hospices responding to the survey (96\%) were aware of National Institute for Health and Clinical Excellence guidelines on nutrition in adults. However, only one-quarter had made changes based on interpretation of the guidelines; (9) the vast majority of respondent hospices $(79 \%)$ did not have a nutrition group or a nutritional policy (72\%); (10) many respondents asked for more teaching or training on nutrition and expressed the need for information sharing and advice.

The group analysed the results of the survey and concluded that more information was needed to understand current hospice practices, which appear to be quite diverse.

The following recommendations are being considered: (1) hospices should have an explicit nutritional policy to ensure quality nutritional care; (2) healthcare professionals who give nutritional advice should receive appropriate training and updating, which is recognised by appropriate professional bodies; (3) hospices should aim to provide nutritional education, counselling and support in inpatient and community settings; (4) hospices may benefit from some dedicated time from a specialist dietitian who would work together with a nutritional lead and a nutritional group to consider national and local issues.

Following the completion of the Nutrition Survey in Hospices, the Food and Nutrition Group has agreed to undertake strategic policy work on nutritional practices in hospices, aimed at increasing the nutritional skills of healthcare professionals by providing training, education and ongoing specialist information and advice on nutrition. To inform the development of the work and, in particular, an appropriate tool for nutritional screening of palliative care patients, the group has encouraged hospices to take part in the British Association of Parenteral and Enteral Nutrition National Nutrition Screening Week 2008. 